\title{
Rotational knee laxity: Reliability of a simple measurement device in vivo
}

\author{
Andrew G Tsai, Volker Musahl*, Hanno Steckel, Kevin M Bell, Thore Zantop, \\ James J Irrgang and Freddie $\mathrm{H} \mathrm{Fu}$
}

Address: Department of Orthopaedic Surgery, University of Pittsburgh, Pittsburgh, PA, USA

Email: Andrew G Tsai - andrew.g.tsai@gmail.com; Volker Musahl* - musahlv@upmc.edu; Hanno Steckel - hanno.steckel@gmail.com; Kevin M Bell - bellkm@upmc.edu; Thore Zantop - thore.zantop@ukmuenster.de; James J Irrgang - irrgangij@upmc.edu;

Freddie H Fu - ffu@upmc.edu

* Corresponding author

Published: 18 March 2008

BMC Musculoskeletal Disorders 2008, 9:35 doi:10.1 186/147|-2474-9-35

This article is available from: http://www.biomedcentral.com/147I-2474/9/35

(c) 2008 Tsai et al; licensee BioMed Central Ltd.

This is an Open Access article distributed under the terms of the Creative Commons Attribution License (http://creativecommons.org/licenses/by/2.0), which permits unrestricted use, distribution, and reproduction in any medium, provided the original work is properly cited.
Received: II June 2007

Accepted: 18 March 2008

\begin{abstract}
Background: Double bundle ACL reconstruction has been demonstrated to decrease rotational knee laxity. However, there is no simple, commercially-available device to measure knee rotation. The investigators developed a simple, non-invasive device to measure knee rotation. In conjunction with a rigid boot to rotate the tibia and a force/moment sensor to allow precise determination of torque about the knee, a magnetic tracking system measures the axial rotation of the tibia with respect to the femur. This device has been shown to have acceptable levels of test re-test reliability to measure knee rotation in cadaveric knees.
\end{abstract}

Methods: The objective of this study was to determine reliability of the device in measuring knee rotation of human subjects. Specifically, the intra-tester reliability within a single testing session, test-retest reliability between two testing sessions, and inter-tester reliability were assessed for II male subjects with normal knees.

Results: The $95 \%$ confidence interval for rotation was less than $5^{\circ}$ for intra-tester, test-retest, and inter-tester reliability, and the standard error of measurement for the differences between left and right knees was found to be less than $3^{\circ}$.

Conclusion: It was found that the knee rotation measurements obtained with this device have acceptable limits of reliability for clinical use and interpretation.

\section{Background}

The anterior cruciate ligament (ACL) is the primary restraint to anterior tibial translation, secondary restraint to valgus rotation, and tertiary restraint to internal tibial rotation [1]. Rotational knee laxity may predict later osteoarthritis $[2,3]$ and is closely correlated with patient discomfort [4]. Though reduced after single-bundle ACL reconstruction [5], rotational laxity may still exist, even though the anterior translation has been adequately restored $[6,7]$. Anatomic double-bundle reconstruction, in contrast, replaces the anteromedial (AM) bundle as well as posterolateral bundle (PL) [8,9]. Anatomic ACL reconstruction may better restore normal knee kinematics in six degrees of freedom (6-DOF) [10-13]. Diagnosis of rotational knee laxity after ACL tears in the office is based on patient history and subjective un-instrumented physi- 
cal examination. Concomitant injury to other ligamentous structures can lead to false positives, and patient guarding can reduce the sensitivity of tests and lead to false negatives.

\section{Un-Instrumented Physical Exams}

Un-instrumented physical examination is the gold standard for assessing knee ligamentous injuries, although these exams are subjective and dependent on examiners skill and experience. The Lachman test, which is performed with the knee at $30^{\circ}$ of flexion, is the most sensitive test [14]. At this flexion angle, the PL bundle is starting to become tight and is the primary restraint to anterior tibial translation. A difference of $>3 \mathrm{~mm}$ in anterior tibial translation as compared to the uninjured, contralateral knee as well as a soft endpoint indicate a positive Lachman test, which is indicative of injury to the ACL, both in the AM and PL bundles [15]. The less-sensitive anterior drawer test is tested with the knee at $90^{\circ}$ of flexion. When performing the anterior drawer test, the examiner draws the proximal tibia forward and uses his thumbs to palpate the tibiofemoral step off; the test is repeated with the foot in neutral, internal, and external rotation. The quality of the end point as well as the difference in translation between the patient's injured and uninjured knees indicates damage to the ACL, particularly the AM bundle, as well as secondary supports [16]. The Slocum test is similar to the anterior drawer test except it tests for rotational laxity and is performed with the foot and tibia internally rotated $30^{\circ}$ and with the tibia externally rotated $15^{\circ}[16,17]$. The internal and external rotation tightens up the lateral and medial ligamentous structures respectively. A positive Slocum test is indicative of anterolateral or anteromedial laxity. The pivot-shift test is the most specific test for ACL injury and is oftentimes only testable during examination under anesthesia (EUA). To administer the pivot-shift test, the tester rotates the patient's tibia inward while the knee is flexed at $30^{\circ}$ [18-20]. The tester then extends and subsequently flexes the knee. If a pivot shift is present, the examiner should feel an anterior subluxation of the knee during extension and a glide, clunk, or gross reduction during flexion, corresponding to grades I, II, or III, respectively $[21,22]$.

\section{Instrumented Physical Exams}

There are several commercially-available arthrometers used clinically to quantify anterior-posterior knee laxity, including the KT-1000 (MEDmetric Corporation, San Diego, CA), Rolimeter (Aircast, Summit, NJ), Acufex Knee Signature System (Acufex Inc., Mansfield, MA), and Stryker Knee Laxity Tester (Stryker Corporation, Kalamazoo, MI) $[16,23,24]$, though the KT-1000 is the most widely used [16]. The Rottometer [25] and Vermont Knee Laxity Device [26] may also be used to determine rotational knee laxity. The Rottometer is a modified chair design with the foot strapped down to a plate; knee rotation is measured with a goniometer. The Rottometer is a simple, easy-to-use device; however, it is not portable and is not capable of measuring off-axis loading. The Vermont Knee Laxity Device is a large, complex device that is capable of accurately measuring knee kinematics and simulating various loading situations. Its size, however, prohibits it from being portable and being used in the office setting. A simple device that measures rotation in a non-invasive manner is the Lars Rotational Laxiometer [27], which is strapped externally to the subjects' tibia. The Lars Rotational Laxiometer, however, is not able to measure the moment applied by the observer during testing and is unable to cancel out coupled motion of the femur; both were suggested as deficiencies by Bleday, et al. Additionally, computer assisted surgery (CAS) devices make it possible for a surgeon to accurately measure kinematics of the knee, but they are costly, complex, and require the patient to undergo surgery and thus can not be used for clinical follow-up [28,29].

There is no simple, commercially available device to measure knee rotation [30,31]. In a previous study, a simple device for non-invasive measurement of rotational laxity was described [32]. This device has been shown to have acceptable levels of test re-test reliability to measure knee rotation in a best case scenario in cadaveric knees. Therefore, the objective of this study was to determine the reliability of the new device to measure knee rotation in human subjects with normal knees. Specifically, the intratester reliability within a single testing session, the testretest reliability between two testing sessions, and the inter-tester reliability were evaluated. It was hypothesized that knee rotation measurements obtained with the new device will have acceptable limits of reliability for clinical use and interpretation.

\section{Methods}

The rotational knee laxity measurement device consists of an Aircast ${ }^{\oplus}$ Foam Walker (Aircast, Summit, NJ) fitted with a 6-DOF universal force/moment sensor (UFS-Model 4015; JR3 Inc. Woodland, CA) and is used in conjunction with a Nest of Birds (NOB, Ascension Technologies, Inc. Burlington, VT) magnetic tracking system [32]. The 6DOF universal force/moment sensor (UFS) is affixed to the sole of the Aircast boot with metal plates and screws. Another metal plate and a handle bar are attached to the front of the load cell, and a liquid-filled bubble-level is secured to the bar for the purpose of aligning the load cell to the ground. The magnetic tracking system consists of a compact NOB chassis, 4 magnetic sensors, and a transducer. The sensors and the transducer communicate with the chassis via cables. A computer system is used to collect motion data from the NOB sensors and monitor the forces and moments of the UFS. Matlab (The Mathworks, 
Natick, MA), a mathematical computing software package, is used to interface with the magnetic sensors and the UFS from the computer.

The study was conducted on human subjects with the prior, written consent of the subjects and the approval of the University of Pittsburgh Institutional Review Board (\#0505098). There were 11 males between the ages of 27 and 35 , with a mean age of 30.3 years. The subjects had an average height of $187 \mathrm{~cm}$ and an average mass of $89.5 \mathrm{~kg}$. The shoe size of the subjects was uniform, between 10.5 and 13 (US men's) with an average of 11.5. Therefore, a medium sized Aircast Foam Walker was chosen to provide snug fit for all subjects. See Table 1 for more details on subjects. Prior to testing with the knee laxity measurement device, each subject underwent examination according to IKDC protocol [21] to ensure that subject had normal knees bilaterally. The examinations included manual Lachman and anterior drawer tests, instrumented Lachman test with Rolimeter, pivot shift test and manual dial test. All subjects were determined knee normal by manual examination (Table 2).

For application of the device on a human subject, the air cells inside the Aircast Foam Walker were inflated to a gauge pressure of $40 \mathrm{mmHg}$ prior to each test. The subject, who was lying supine on an examination table, confirmed a snug fit of the device without being uncomfortable. The NOB is capable of tracking the position and orientation of the tibia, femur, and boot simultaneously. Placement of the magnetic sensors on the subject's leg is accomplished with hook and loop fasteners attached to fabric straps. The magnetic sensors were placed on specially marked areas on the anterior surface of the Aircast boot, the medial surface of the proximal tibia $1 \mathrm{~cm}$ distal from the tibiofemoral joint line, and the anterior surface of the thigh. The actual placement of the sensors was indicated on the skin with a non-permanent skin marker for the purpose of determining if the magnetic tracker had been severely dis- turbed between tests. A handle bar mounted on the UFS allowed the tester to rotate the boot easily as well as support the lower leg at the appropriate angle of knee flexion, and a bubble-level mounted on the handle bar allowed the tester to achieve a consistent starting point and sensor alignment with respect to the ground (Figure 1). A section of 2" polyvinyl chloride pipe (PVC) mounted vertically on the side of the examination table prevented each subject's hip and leg from externally rotating through the hip joint during examination. Additionally, during the $30^{\circ}$ knee flexion tests, a raised, support platform was placed under the thigh to angle the leg and allow the tester to more easily maintain the proper flexion angle of the knee. The software interface (Figure 2) and computer provided useful audio-visual feedback to the tester to indicate when moments of 2, 4, and $6 \mathrm{Nm}$ had been measured at the load cell. At 2, 4, and $6 \mathrm{Nm}$ of torque, tones with increasingly higher frequencies played through the speakers as a guide for the tester. Also at $6 \mathrm{Nm}$, the graph displayed on the screen changed from green to red as a visual indication that the target load was achieved.

The relative motion of the tibia with respect to the femur is considered internal and external rotation of the knee and is the method by which the measurement device operates. The system utilizes a Cardan angle sequence based on Grood and Suntay conventions [33], and the coordinate system is aligned with the long axis of the tibia through the bubble level. Two of the three rotation angles are always held constant during testing, so this methodology allows repeatable, efficient readings consistent with current manual testing without adding to the testing time or the requisite technical knowledge of the clinician. Because the device uses three sensors, it can more faithfully record motions of the tibia. When the observer is ready to begin the test, he aligns the boot position level to the ground as indicated by the bubble level. The computer accepts the aligned position as the starting position, and then the observer performs cycles of internal and external

Table I: Subject Statistics

\begin{tabular}{|c|c|c|c|c|c|}
\hline Subject & Age & Height (cm) & Shoe size (US) & Weight (kg) & BMI \\
\hline $\mathbf{I}$ & 31 & 188 & 12 & 88.5 & 25 \\
\hline 2 & 30 & 188 & 12 & 86.2 & 24.4 \\
\hline 3 & 34 & 196 & 13 & 88.5 & 23.1 \\
\hline 4 & 35 & 191 & 12 & 83.0 & 23.1 \\
\hline 5 & 28 & 188.0 & 10.5 & 90.7 & 25.7 \\
\hline 6 & 29 & 188.0 & 13 & 104.3 & 29.5 \\
\hline 7 & 27 & 185 & 10.5 & 86.2 & 25.1 \\
\hline 8 & 31 & 180 & II & 88.5 & 27.2 \\
\hline 9 & 27 & 178 & 10.5 & 86.2 & 27.3 \\
\hline 10 & 31 & 196 & 13 & 93.0 & 24.3 \\
\hline II & 29 & 180 & 11 & 88.5 & 27.2 \\
\hline
\end{tabular}

Table I shows age, height, shoe size, weight, and BMI of all subjects. 
Table 2: Manual Examination Data of Subjects Prior to Test (all subjects tested same bilaterally)

\begin{tabular}{|c|c|c|c|c|c|c|c|}
\hline \multirow[b]{2}{*}{ Subject } & \multirow[b]{2}{*}{ Manual Lachman (mm) } & \multirow[b]{2}{*}{$\begin{array}{l}\text { Instrumented Lachman } \\
\text { with Rolimeter }(\mathrm{mm})\end{array}$} & \multirow[b]{2}{*}{ Pivot Shift } & \multicolumn{4}{|c|}{ Manual Dial Test } \\
\hline & & & & internal $30^{\circ}$ & external $30^{\circ}$ & internal $90^{\circ}$ & external $90^{\circ}$ \\
\hline $\mathbf{I}$ & I & 2 & normal & 10 & 20 & 10 & 20 \\
\hline 2 & I & 2 & normal & 10 & 15 & 10 & 15 \\
\hline 3 & I & 3 & normal & 10 & 10 & 10 & 15 \\
\hline 4 & I & 2 & normal & 10 & 20 & 10 & 20 \\
\hline 5 & 1 & 2 & normal & 10 & 15 & 15 & 20 \\
\hline 6 & 1 & 2 & normal & 5 & 10 & 5 & 10 \\
\hline 7 & I & I & normal & 5 & 5 & 5 & 5 \\
\hline 8 & I & I & normal & 5 & 10 & 5 & 10 \\
\hline 9 & I & 1 & normal & 10 & 15 & 15 & 20 \\
\hline 10 & 1 & 2 & normal & 10 & 15 & 15 & 20 \\
\hline II & 1 & 2 & normal & 10 & 15 & 10 & 15 \\
\hline
\end{tabular}

Table 2 shows results from manual examination prior to testing the subjects with the new device. Data include manual Lachman, instrumented Lachman with a Rolimeter measurement device, the pivot shift test, and manual dial test. Manual dial test was tested at $30^{\circ}$ and $90^{\circ}$ and the data represent results for internal and external rotation. All subjects tested the same bilaterally.

rotation. The initial position of the tibia sensor relative to the femur sensor is then compared with the relative position for each subsequent sample. By this method, undesired femoral motion (for example, hip rotation) is able to be mathematically eliminated from coupled tibia motion to give only the relative motion of the tibia to the femur. Additionally, the sensor attached to the boot allows the load cell to account for changing orientations of the boot, which may be slightly different from those of the subjects' tibia. By being able to see the loads on the computer screen, the tester is able to see if unintended off-axis loading is being applied.

Three aspects of the device were tested in determining the reliability of the device. The first was intra-tester reliability within a single testing session. During each trial, at $90^{\circ}$ and $30^{\circ}$ of knee flexion, the examiner took five measurements for internal-external rotation, and the reliability within those five trials was observed. Another aspect was test-retest reliability. To gauge test-retest reliability, a single examiner removed the device after measuring the internal-external rotation, and, a short time later, replaced the device and re-measured the internal-external rotation. The final aspect was the inter-tester reliability. Inter-tester reliability was measured by comparing the measurements of a secondary examiner with those of the primary examiner.

Statistical analysis was performed using Statistical Package for the Social Sciences (SPSS Inc., Chicago, IL). To assess intra-tester, test re-test and inter-tester reliability, intraclass correlation coefficients (ICC) were calculated. The ICC was calculated with formula 2,1 for single measures agreement (for intra-tester reliability) and ICC formula 2,5 for average measures agreement [34]. The ICC value was further used to estimate the standard error of measurement (SEM), which is defined as the standard deviation of the measurements multiplied by the square root of one minus the ICC. The 95\% confidence intervals for the standard error of measurement are calculated as $(1.96 *$ SEM) and are interpreted as the degree of uncertainty of an individual's observed measurement [35].

\section{Results}

There were no adverse effects noted by the subjects, specifically there were no neurovascular symptoms, no skin irritation, and no adverse effects regarding the amount of applied moment. The total testing time per subject was approximately 20-25 minutes. The pressure in the air cells of the boot was monitored constantly and was consistent between tests, as long as the boot was not removed. Therefore, the air cells were deflated and re-inflated to 40 mmHg whenever the boot was removed or adjusted.

Data for all subjects is summarized in Table 3 . The total axial rotation for $\mathrm{N}=22$ knees was $18.5^{\circ} \pm 4.7^{\circ}$ at $90^{\circ}$ of knee flexion and $25.8^{\circ} \pm 5.9^{\circ}$ at $30,^{\circ}$ of knee flexion. For intra-tester reliability within one testing session with knee flexion of $30^{\circ}$ and $90^{\circ}$, the single measure ICC's were both $>0.95$, with associated SEM's $<1^{\circ}$ and a 95\% confidence interval's $<2.0^{\circ}$. For inter-tester reliability at $90^{\circ}$ of knee flexion ( $\mathrm{n}=21$, data from 1 knee was lost), the average measures ICC and SEM were 0.88 and $1.6^{\circ}$, respectively, resulting in a $95 \%$ confidence interval of $3.2^{\circ}$. At $30^{\circ}$ of knee flexion $(\mathrm{n}=22)$, the average measures ICC and SEM for inter-tester reliability were 0.81 and $2.6^{\circ}$ respectively, yielding a 95\% confidence interval of $5.1^{\circ}$. For $90^{\circ}$ of knee flexion, the average measures ICC and SEM for test-retest reliability were 0.77 and $1.9^{\circ}$, respectively, for a $95 \%$ confidence interval of $3.8^{\circ}$. 


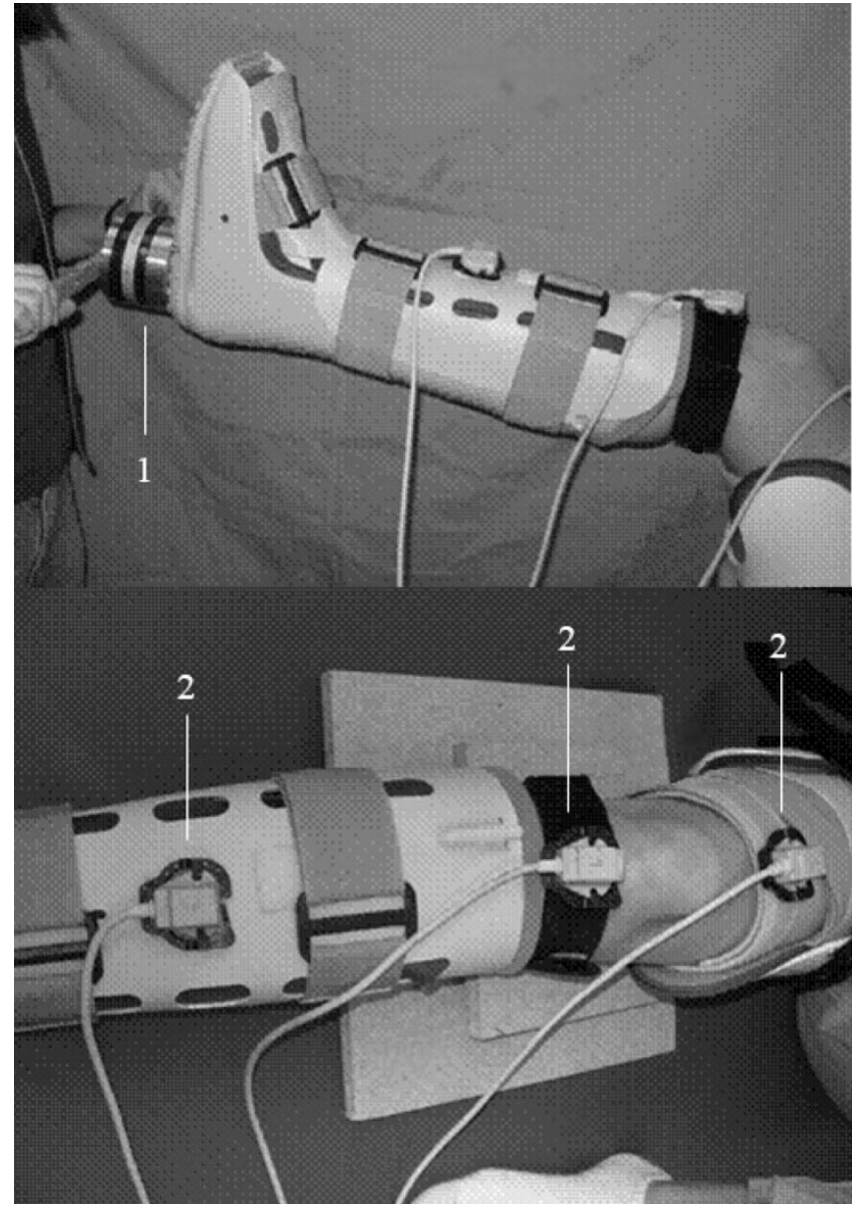

Figure I

Knee Laxity Measurement Device. This picture depicts the side view and anterior view of the Knee Laxity Measurement Device in use. Shown are the 6-DOF universal force/ moment sensor and handle bar (I) attached to the Aircast boot. The three magnetic trackers (2) are attached to the boot, tibia, and femur to record measurement of rotational knee laxity.

The average side to side difference in total internal-external rotation of the tibia between normal knees was $3.5^{\circ}$. To estimate the magnitude of the differences to be expected between normal knees, we used the ICC to calculate the level of agreement in total tibial rotation between the right and left sides as well as the SEM. The ICC's were all greater than 0.75 and the SEM's were all less than $2^{\circ}$.

\section{Discussion}

In the late 1960's and early 1970's, rotatory laxity of the knee as a consequence of ACL tears began to receive attention [17]. Clinical tests for assessment of rotational laxity, such as the pivot shift test or the Losee test were subsequently developed $[16,17,30,36]$. Assessment of rotational laxity has now become standard practice in most institutions, highlighting the need for standardization and consistent documentation. Daniel et al. developed an instrumented test for measurement of anterior-posterior knee laxity in the 1980's [15], which has since become the gold standard for reporting outcomes of ACL reconstructions [37-39]. Currently, there are efforts being made to develop instrumented tests for rotational knee laxity $[25,28,40]$. With the concept of anatomic ACL reconstruction, there is a demand for consistent documentation of rotational laxity. The objective of the present study was to determine the reliability of a simple device, previously validated in vitro [32], for measuring knee rotational laxity in vivo. Such a device should yield measurements of knee laxity that are consistent during a single testing session for a single tester, consistent for a single tester over multiple testing sessions, and consistent between testers. Therefore, intra-tester reliability, test-retest reliability, and inter-tester reliability were calculated in order to gauge reliability of the system. The results support the hypothesis that the device has acceptable limits of reliability, and specifically, repeatability of the device was found to be within $5^{\circ}$ of rotation. The highest inter-tester reliability was observed at $30^{\circ}$, which the authors believe may be attributed to excessive hip and thigh rotation during testing. The clinical significance of $5^{\circ}$ of measurement error when measuring differences between injured and noninjured knees or within an injured knee over time before and after treatment has yet to be determined. We currently have ongoing studies that are designed to determine if the ability to detect differences of $5^{\circ}$ of tibial rotation is clinically meaningful in patients following ACL, PCL and posterolateral corner injury and surgery.

Determining the reliability of the device was performed with calculations of ICC and SEM. ICC is used as a measure of consistency between measurements, such as between two different observers. The SEM and associated $95 \%$ confidence interval are estimations of measurement precision of the device. For example, if the measured rotation of an individual is $15^{\circ}$, and a $95 \%$ confidence interval of $3.2^{\circ}$ was calculated previously, as was the case for inter-tester reliability at $90^{\circ}$ of flexion, then one can conclude that 95 times out of 100 the individual's true score lies within $\pm 3.2^{\circ}$ of the measured value. Thus, if the individuals measured score was $20^{\circ}$, the $95 \%$ confidence interval for the individual's true score is $16.8^{\circ}$ to $23.2^{\circ}$.

In the case of trauma to the knee, manual testing by a clinician can help diagnose specific ligamentous injury. Manual testing of rotational laxity of the knee, such as with the pivot-shift test, is highly variable and dependent on the tester's experience and ability to detect abnormal knee motions. The shift is described as a combined posterior translation and/or external rotation, but the presence of the two motions is inconsistent between subjects [5]. 


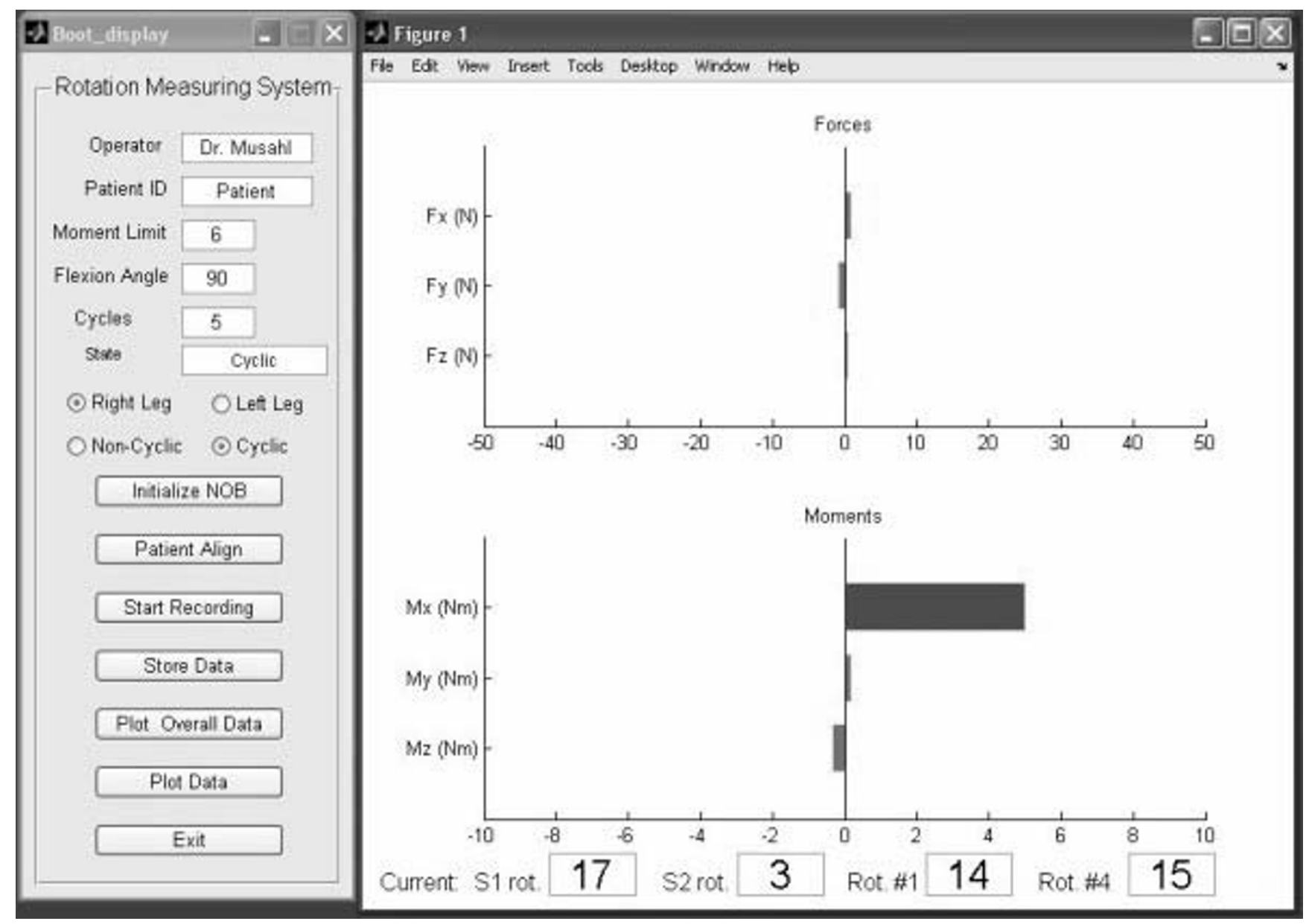

\section{Figure 2}

Screen-shot from Software Interface. The computer software interface displays the forces and moments for 6 degrees of freedom. Tibial rotation is also displayed. The visual feedback, as well as audio feedback, assists the investigator in achieving a consistent moment while reducing off-axis loading.

Instrumented clinical tests, such as the instrumented Lachman and anterior-drawer tests performed with the KT-1000 are sufficient in measuring anterior-posterior translation but cannot gauge rotational laxity. Tests performed with rigidly fixated electromagnetic sensors [5] or computer navigation [28] can accurately measure rotational kinematics, but such tests are invasive and impractical in the office setting. A simple-to-use, clinicallyrelevant device for rotational laxity measurement has yet to become commercially available.

Studies have shown that rotational knee laxity is highly variable between subjects and can range anywhere from $20^{\circ}$ to $65^{\circ}$ of rotation depending on flexion angle and testing method, so a reliable instrument for measuring knee laxity would be needed to detect abnormal rotational motion [25,41-43]. In a recent in vivo study [25], a similar external measurement device, the Rottometer, was compared to RSA results and found to have systematic error of around $100 \%$. At $90^{\circ}$ of flexion and $6 \mathrm{Nm}$ of torque, the Rottometer device recorded $21^{\circ}$ and $27^{\circ}$ of internal and external rotation, respectively, while RSA recorded $10^{\circ}$ and $16^{\circ}$, respectively. That error seems to arise because measurements were made at the foot without taking into account ankle rotation. Our results of $18.5^{\circ}$ total rotation may understate the rotation because of skin and soft tissue artifacts. Though accuracy can still be improved, reliability of the device has been demonstrated within the testing parameters.

The new device presented in this study has potential use in clinic because it is portable, non-invasive, and requires no specific skills to operate. The ability to measure knee laxity with a simple device could be advantageous to both patients and physicians. Its ability to measure rotational laxity, versus other devices that measure anterior-posterior 
Table 3: Results on rotational laxity

\begin{tabular}{|c|c|c|c|c|c|}
\hline & $90^{\circ}$, observer I, time I & $90^{\circ}$, observer 2 , time I & $30^{\circ}$, observer I, time I & $30^{\circ}$, observer 2 , time I & $90^{\circ}$, observer 1 , time 2 \\
\hline Subject I, right & 17.9 & 16.0 & 27.6 & 33.5 & 23.4 \\
\hline Subject I, left & 15.5 & 14.3 & 27.1 & 34.8 & 16.9 \\
\hline Subject 2 , right & 19.1 & 16.0 & 22.2 & 32.2 & 16.3 \\
\hline Subject 2, left & 24.4 & 20.4 & 27.8 & 30.7 & 17.0 \\
\hline Subject 3 , right & 17.2 & -- & 20.4 & 25.9 & 16.6 \\
\hline Subject 3, left & 16.7 & 18.9 & 25.1 & 32.5 & 15.8 \\
\hline Subject 4, right & 14.6 & 17.0 & 17.6 & 29.1 & 15.7 \\
\hline Subject 4 , left & 16.3 & 20.2 & 22.6 & 30.3 & 15.76 \\
\hline Subject 5 , right & 13.5 & 19.1 & 38.3 & 39.1 & 13.7 \\
\hline Subject 5, left & 11.3 & 13.8 & 37.5 & 40.3 & 14.0 \\
\hline Subject 6 , right & 15.5 & 17.8 & 19.4 & 22.3 & 20.2 \\
\hline Subject 6, left & 12.1 & 16.7 & 22.4 & 21.7 & 16.2 \\
\hline Subject 7 , right & 26.8 & 26.4 & 25.9 & 27.9 & 21.6 \\
\hline Subject 7 , left & 18.1 & 17.9 & 15.5 & 18.4 & 19.8 \\
\hline Subject 8 , right & 17.0 & 21.0 & 37.0 & 38.4 & 20.0 \\
\hline Subject 8 , left & 26.6 & 32.4 & 28.5 & 29.3 & 24.2 \\
\hline Subject 9 , right & 26.6 & 26.0 & 28.1 & 30.2 & 21.9 \\
\hline Subject 9 , left & 25.4 & 28.8 & 26.0 & 28.5 & 22.7 \\
\hline Subject 10 , right & 20.1 & 20.0 & 27.1 & 31.5 & 16.0 \\
\hline Subject 10 , left & 15.1 & 20.3 & 23.8 & 27.2 & 14.6 \\
\hline Subject II, right & 20.0 & 21.4 & 23.5 & 26.7 & 21.2 \\
\hline Subject II, left & 18.3 & 19.3 & 23.9 & 24.0 & 24.4 \\
\hline
\end{tabular}

Table 3 shows the data for all subjects, both left and right knees. Column I of the data shows rotation at $90^{\circ}$ of knee flexion for observer I at time I. Column 2 shows rotation at $90^{\circ}$ for observer 2 at time I. Columns 3 and 4 are the data for observers I and 2 at time I at $30^{\circ}$ of knee flexion. Column 5 is the data for $90^{\circ}$ of knee flexion for observer I at time 2 .

translation, can enhance a physician's ability to objectively assess knee injuries by complementing current tests. Rotational laxity may be present even in the absence of abnormal translational movements after single bundle ACL reconstruction. Therefore, during surgical reconstruction of the ACL, addition of the PL bundle may correct the rotational laxity [10-13], but measurement of the rotation still remains an issue.

The device and methodology presented were originally adapted from a prior, cadaveric study [32]. The investigators also conducted a pilot study involving volunteer subjects and used the results from the pilot study to improve the device and test procedure for the current study, since the results obtained during the pilot study were inconsistent. The pilot study yielded a test-retest ICC of 0.73 and a $95 \%$ confidence interval of $15^{\circ}$ for total rotation. Based on the results, the investigators found it necessary to standardize the placement of the electromagnetic trackers to ensure better results from one test to another. Other adjustments were made to the device and protocol based on specific outcomes of the pilot study. The pilot study varied the pressure in the air cells from 0 to $40 \mathrm{mmHg}$ in order to identify the importance of air cell pressure; pressure in the air cells was found to significantly influence the results of the trials. Pressure was, therefore, carefully monitored during this experiment to ensure the cells were inflated to a consistent pressure of $40 \mathrm{mmHg}$ between tri- als. Also during the pilot study, the relative movement of the boot versus the tibia was monitored, and it was found that the boot moved around $30^{\circ}$ relative to the tibia. To improve repeatability of the device, a medium sized boot was used in this study, versus a large sized boot in the pilot, which reduced movement between the subject's foot and the boot. The large boot fits male patients with shoe sizes from 10-13 according to the manufacturer, but it was found that the medium boot, which the company suggests for shoe sizes $7-10$, gave a more snug fit and was not uncomfortable. Other changes made between the two studies included placement of the NOB transmitter. To improve accuracy of the magnetic tracking system, the transmitter was monitored to ensure it was placed between 10-24 inches from the sensors [44]. Finally, improvements were made to the computer's user interface to increase the visibility of the readout from the UFS (Figure 2). The purpose of the improved display was to allow the tester to compensate for incidental off-axis loading and allow the tester to more precisely control the amount of force on the subjects' knees. All the improvements appear to have improved the overall reliability of the device.

Limitations of this study include accuracy and consistency of measured bone movement due to skin artifacts. Though the Aircast boot locks the ankle in place and the air cells limit the movement of soft tissue, skin artifacts 
may diminish the device's ability to measure the actual movement of the tibia relative to the femur at the knee [45]. Because the magnetic trackers are attached with fabric strips to the surface of the skin on the femur and thigh, movement of skin, fat, or muscle around the bone is a source of error. Attaching the magnetic sensors to the most bony or muscular portions of the leg may provide the most reliable results. Since the measurements are taken from the femur and tibia, associated hip, boot, and ankle movements during the knee rotation, should not alter the knee laxity measurements. Also, since the device depends on the NOB magnetic tracking system for measurements, the limitations of the NOB become limitations of the device. The accuracy of any magnetic tracking system is sensitive to ferrous materials and interference from electromagnetic devices in the general vicinity, therefore, care should be taken to minimize interference from metallic or electromagnetic sources. The results of repeatability may have been affected since the investigators marked the subjects' skin with a marker to indicate the placement of the magnetic trackers.

\section{Conclusion}

In conclusion, the new device appears to be repeatable within $5^{\circ}$ of rotation in subjects with a normal knee. The new device is simple, portable, and easy to use. Future studies are planned to address the effectiveness of the device on patients with unilateral chronic ligamentous insufficiency to determine the device's ability to distinguish between normal and injured knees.

\section{Competing interests}

The author(s) declare that they have no competing interests.

\section{Authors' contributions}

AT assisted with experimental methods, subject testing, data analysis, and drafting of the manuscript. VM conceived of the study, acted as primary physician conducting testing, recruited subjects, analyzed results, and helped draft the manuscript. HS assisted in testing of subjects as a secondary observer and drafting the manuscript. KB assisted with study design, data acquisition, and drafting of the manuscript. TZ participated in initial design of the device and the study, pilot study testing, and drafting of the manuscript. JI assisted with designing the study, statistical analysis, and drafting of the manuscript. FF assisted with study conception and drafting of the manuscript. All authors read and approved the final manuscript.

\section{Acknowledgements}

We acknowledge the support of the Department of Orthopaedic Surgery and the Physical Therapy Research Laboratory at the University of Pittsburgh. The provision of materials by the Hanger Orthopedic Group Inc. is greatly appreciated. Funding was provided through the Albert Ferguson Jr. research grant through the University of Pittsburgh, Department of Orthopaedic Surgery.

\section{References}

I. Girgis FG, Marshall JL, Monajem A: The cruciate ligaments of the knee joint. Anatomical, functional and experimental analysis. Clin Orthop Relat Res 1975:216-23I.

2. Fithian DC, Paxton EW, Stone ML, Luetzow WF, Csintalan RP, Phelan $D$, Daniel DM: Prospective trial of a treatment algorithm for the management of the anterior cruciate ligament-injured knee. Am J Sports Med 2005, 33(3):335-346.

3. Jonsson H, Riklund-Ahlstrom K, Lind J: Positive pivot shift after ACL reconstruction predicts later osteoarthrosis: 63 patients followed 5-9 years after surgery. Acta orthopaedica Scandinavica 2004, 75(5):594-599.

4. Leitze Z, Losee RE, Jokl P, Johnson TR, Feagin JA: Implications of the pivot shift in the ACL-deficient knee. Clin Orthop Relat Res 2005:229-236.

5. Bull AM, Earnshaw PH, Smith A, Katchburian MV, Hassan AN, Amis AA: Intraoperative measurement of knee kinematics in reconstruction of the anterior cruciate ligament. J Bone Joint Surg $\mathrm{Br}$ 2002, 84(7): |075-108|.

6. Tashman S, Collon D, Anderson K, Kolowich P, Anderst W: Abnormal rotational knee motion during running after anterior cruciate ligament reconstruction. Am J Sports Med 2004, 32(4):975-983.

7. Yagi M, Wong EK, Kanamori A, Debski RE, Fu FH, Woo SL: Biomechanical analysis of an anatomic anterior cruciate ligament reconstruction. Am J Sports Med 2002, 30(5):660-666.

8. Cha PS, Brucker PU, West RV, Zelle BA, Yagi M, Kurosaka M, Fu FH: Arthroscopic double-bundle anterior cruciate ligament reconstruction: an anatomic approach. Arthroscopy 2005, 2I( I0): I 275.

9. Petersen $W$, Zantop $T$ : Anatomy of the anterior cruciate ligament with regard to its two bundles. Clin Orthop Relat Res 2007, 454:35-47.

10. Aglietti P, Giron F, Cuomo P, Losco M, Mondanelli N: Single-and double-incision double-bundle $A C L$ reconstruction. Clin Orthop Relat Res 2007, 454:108-II 3.

II. Amis AA, Bull AM, Lie D: Biomechanics of Rotational Instability and Anatomic Anterior Cruciate Ligament Reconstruction. Operative Techniques in Orthopaedics 2005, I 5(I):29-35.

12. Musahl V, Plakseychuk A, VanScyoc A, Sasaki T, Debski RE, McMahon $\mathrm{PJ}$, Fu FH: Varying femoral tunnels between the anatomical footprint and isometric positions: effect on kinematics of the anterior cruciate ligament-reconstructed knee. Am J Sports Med 2005, 33(5):7|2-7|8.

13. Yagi M, Kuroda R, Nagamune K, Yoshiya S, Kurosaka M: Doublebundle ACL reconstruction can improve rotational stability. Clin Orthop Relat Res 2007, 454:100-107.

14. Katz JW, Fingeroth RJ: The diagnostic accuracy of ruptures of the anterior cruciate ligament comparing the Lachman test, the anterior drawer sign, and the pivot shift test in acute and chronic knee injuries. Am J Sports Med 1986, I 4(I):88-9I.

15. Daniel DM, Malcom LL, Losse G, Stone ML, Sachs R, Burks R: Instrumented measurement of anterior laxity of the knee. J Bone Joint Surg Am 1985, 67(5):720-726.

16. Irrgang JJ, Safran MR, Fu FH: The Knee: Ligamentous and Meniscal Injuries. In Athletic Injuries and Rehabilitation Edited by: JE Z, DJ M, WS Q. Philadelphia W.B Saunders Company; 1996:623-692.

17. Slocum DB, Larson RL: Rotatory instability of the knee. Its pathogenesis and a clinical test to demonstrate its presence. Bone Joint Surg Am 1968, 50(2):21 I-225.

18. Bach BR Jr, Warren RF, Wickiewicz TL: The pivot shift phenomenon: results and description of a modified clinical test for anterior cruciate ligament insufficiency. Am J Sports Med 1988, 16(6):57I-576.

19. Bull AM, Andersen HN, Basso O, Targett J, Amis AA: Incidence and mechanism of the pivot shift. An in vitro study. Clin Orthop Relat Res 1999:219-231.

20. Galway HR, Maclntosh DL: The lateral pivot shift: a symptom and sign of anterior cruciate ligament insufficiency. Clin Orthop Relat Res 1980:45-50. 
21. Hefti F, Muller W, Jakob RP, Staubli HU: Evaluation of knee ligament injuries with the IKDC form. Knee Surg Sports Traumatol Arthrosc 1993, I(3-4):226-234.

22. Irrgang J], $\mathrm{Ho} \mathrm{H}$, Harner $\mathrm{CD}$, Fu FH: Use of the International Knee Documentation Committee guidelines to assess outcome following anterior cruciate ligament reconstruction. Knee Surg Sports Traumatol Arthrosc 1998, 6(2): 107-II4.

23. Balasch H, Schiller M, Friebel H, Hoffmann F: Evaluation of anterior knee joint instability with the Rolimeter. A test in comparison with manual assessment and measuring with the KT1000 arthrometer. Knee Surg Sports Traumatol Arthrosc 1999, 7(4):204-208.

24. Highgenboten CL, Jackson A, Meske NB: Genucom, KT-1000, and Stryker knee laxity measuring device comparisons. Device reproducibility and interdevice comparison in asymptomatic subjects. Am J Sports Med 1989, I 7(6):743-746.

25. Almquist PO, Arnbjornsson A, Zatterstrom R, Ryd L, Ekdahl C, Friden $T$ : Evaluation of an external device measuring knee joint rotation: an in vivo study with simultaneous Roentgen stereometric analysis. J Orthop Res 2002, 20(3):427-432.

26. Uh BS, Beynnon BD, Churchill DL, Haugh LD, Risberg MA, Fleming $B C$ : A new device to measure knee laxity during weightbearing and non-weightbearing conditions. J Orthop Res 200I, 19(6): | |85-|| 191.

27. Bleday RM, Fanelli GC, Giannotti BF, Edson CJ, Barrett TA: Instrumented measurement of the posterolateral corner. Arthroscopy 1998, I4(5):489-494.

28. Colombet P, Robinson J, Christel P, Franceschi JP, Djian P: Using navigation to measure rotation kinematics during $A C L$ reconstruction. Clin Orthop Relat Res 2007, 454:59-65.

29. Musahl V, Plakseychuk A, Fu FH: Current opinion on computeraided surgical navigation and robotics: role in the treatment of sports-related injuries. Sports Med 2002, 32(13):809-818.

30. Slocum DB, James SL, Larson RL, Singer KM: Clinical test for anterolateral rotary instability of the knee. Clin Orthop Relat Res 1976:63-69.

31. Zaffagnini S, Martelli S, Falcioni B, Motta M, Marcacci M: Rotational laxity after anterior cruciate ligament injury by kinematic evaluation of clinical tests. Journal of medical engineering \& technology 2000, 24(5):230-236.

32. Musahl V, Bell KM, Tsai AG, Costic RS, Allaire R, Zantop T, Irrgang JJ, Fu FH: Development of a simple device for measurement of rotational knee laxity. Knee Surg Sports Traumatol Arthrosc 2007, I5(8): 1009-1012.

33. Grood ES, Suntay W]: A joint coordinate system for the clinical description of three-dimensional motions: application to the knee. J Biomech Eng 1983, 105(2): 136-| 44.

34. Shrout PE, Fleiss JL: Intraclass correlations: Uses in assessing rater reliability. Psychological Bulletin 1979, 86(2):420-428.

35. Crocker L, Algina J: Introduction to classical \& modern test theory. Fort Worth: Harcourt Brace Jovanovich College Publishers; 1986.

36. Losee RE: Concepts of the pivot shift. Clin Orthop Relat Res 1983:45-51.

37. Fu FH, Bennett $\mathrm{CH}, \mathrm{Ma} \mathrm{CB}$, Menetrey J, Lattermann C: Current trends in anterior cruciate ligament reconstruction. Part II. Operative procedures and clinical correlations. Am J Sports Med 2000, 28(I): I24-130.

38. Howell SM, Deutsch ML: Comparison of endoscopic and twoincision techniques for reconstructing a torn anterior cruciate ligament using hamstring tendons. Arthroscopy 1999, I 5(6):594-606.

39. Shelbourne KD, Stube KC: Anterior cruciate ligament (ACL)deficient knee with degenerative arthrosis: treatment with an isolated autogenous patellar tendon $A C L$ reconstruction. Knee Surg Sports Traumatol Arthrosc 1997, 5(3): I 50 - I56.

40. Kubo S, Muratsu H, Yoshiya S, Mizuno K, Kurosaka M: Reliability and usefulness of a new in vivo measurement system of the pivot shift. Clin Orthop Relat Res 2007, 454:54-58.

4I. Draganich LF, Sathy MR, Reider B: The effect of thigh and goniometer restraints on the reproducibility of the genucom knee analysis system. Am J Sports Med 1994, 22(5):627-63I.

42. McQuade KJ, Sidles JA, Larson RV: Reliability of the Genucom Knee Analysis System. A pilot study. Clin Orthop Relat Res 1989:216-219.
43. Quinn TP, Mote CD Jr, Skinner HB: The effect of ankle constraint on the torsional laxity of the knee during internal-external rotation of the foot. J Biomech I991, 24(7):5 I I-525.

44. Milne AD, Chess DG, Johnson JA, King G]: Accuracy of an electromagnetic tracking device: a study of the optimal range and metal interference. J Biomech 1996, 29(6):791-793.

45. Benoit DL, Ramsey DK, Lamontagne M, Xu L, Wretenberg P, Renstrom $P$ : Effect of skin movement artifact on knee kinematics during gait and cutting motions measured in vivo. Gait \& posture 2006, 24(2): 152-164.

\section{Pre-publication history}

The pre-publication history for this paper can be accessed here:

http://www.biomedcentral.com/1471-2474/9/35/prepub
Publish with Biomed Central and every scientist can read your work free of charge

"BioMed Central will be the most significant development for disseminating the results of biomedical research in our lifetime. "

Sir Paul Nurse, Cancer Research UK

Your research papers will be:

- available free of charge to the entire biomedical community

- peer reviewed and published immediately upon acceptance

- cited in PubMed and archived on PubMed Central

- yours - you keep the copyright 